\title{
PREDICTABILITY OF REGENERATION PROCEDURES
}

\author{
Raul G. Caffesse, D.D.S., M.S., Dr. Odont., Dr.Dr.h.c. \\ Distinguished Professor and Head, Division of Periodontics \\ The University of Texas-Houston \\ Health Science Center \\ Dental Branch
}

\section{Predictability of Guided Tissue Regeneration Procedures}

Guided Tissue Regeneration has been incorpo rated as another technique within the armamentarium of the periodontists to treat advanced localized disease.

Since the biological principles governing guided tissue regeneration were observed in the eighties, significant amount of research, both animal and clinical, has been published supporting the benefits produced by this technique in specific periodontal problems. It is agreed that GTR represents a specific treatment for specific defects. Class II furcation defects and intrabony pockets represent the selections of choice ${ }^{1}$. Loss of clinical attachment should be at least 4 millimeters and, if dealing with intrabony pockets the bony defect should be at least 4 millimeters in depth.

It has been documented that the outcome of therapy will depend on several local environmental factors, like the overall level of oral hygiene, the depth and width of the defect, the clinical attachment loss, and the exposure of the membrane ${ }^{2)}$. The success will be directly related to the initial attachment loss, the depth of the defect, and the effectiveness of oral hygiene. Conversely, the success will be inversely related to the width of the defect and the early exposure of the membrane.

Furthermore, there are behavioral factors which influence the outcome of therapy, being smoking the most significant risk factor considered at the present to influence the results achieved ${ }^{3)}$

At the present the clinician has the choice to use either non-resorbable or resorbable membranes ${ }^{4}$. The time-proven, gold standard for GTR is the non-resorbable expanded polytetrafluorethylene (e-PTFE) membrane. Having been the first membrane introduced to the market is the one that counts with most of the scientific literature to prove its effectiveness.

Animal research from our laboratory has shown the regeneration of the attachment apparatus in beagle dogs with natural periodontitis, with the formation of new bone, new cementum and new periodontal ligament fibers. Linear measurements recorded from reference notches to specific landmarks ${ }^{5}$, as well as surface measurements registered in square millimeters using the furcation defect as a model ${ }^{6}$, indicate the statistically superior results achieved in regeneration when GTR procedures are compared to results obtained with an open flap debridement used as a negative control.

While the latter will heal mainly by mean of a long junctional epithelium, the GTR approach will restore a true attachment in an area previously exposed to the periodontal pocket ${ }^{5,6}$.

Clinical studies evaluating the results obtained with GTR using the e-PTFE membrane have documented superior results to those achieved with an open flap debridement.

Treating Class II furcations it has been reported that the probing pocket depth reduction achieved will almost double that obtained with a flap, and that the gain in clinical attachment will be around 2 to $3 \mathrm{~mm}$, while there will be practically no change with the flap ${ }^{7,88}$.

The treatment of intrabony pockets has also resulted in significant improvements compared to a 
flap control. The probing pocket depth reduction could reach up to $6 \mathrm{~mm}$ with gains in clinical attachment of $4 \mathrm{~mm}$ or more ${ }^{8)}$.

Reports published documenting follow-ups of up to 5 years after treatment give proof of the stability of the results achieved, providing good maintenance is carried out ${ }^{9,10)}$. It is necessary to emphasize that with or without a GTR technique, the clinician is treating an advanced condition of a chronic disease, and that it can be controlled but not cured, and regular supportive therapy, maintenance, becomes mandatory to be able to provide long term stable results $^{11)}$.

It is evident that in order to achieve the desired results with GTR it is necessary to obtain two goals : 1) to allow the proliferation of granulation tissue from the periodontal membrane and, possibly bone marrow spaces, and 2) to block the proliferation of those tissues which could interfere with the coronal proliferation of the periodontal ligament, i.e. gingival epithelium and gingival connective tissue $^{1)}$. To fulfill the first goal it is necessary that the membrane maintains the space underneath. Spacemaking becomes mandatory for the success of the procedure. If the bony defect being treated does not have spacemaking capabilities, the possibility of the collapse of the membrane needs to be addressed.

A filler material needs to be placed underneath the membrane to assure the maintenance of the space. Preference will be given to a synthetic resorbable implant, like a resorbable hydroxyapatite (Osteogen) or an unorganic bovine bone graft (BioOss). Both of them give excellent results in assuring space maintenance under the membrane so the principles of GTR could be fulfilled. The other option now-a-days is the use of a titanium reinforced membrane (TR-GTPM). This e-PTFE membrane has a core of titanium incorporated in its structure. The titanium can be bent, thus giving shape to the membrane and maintaining it through the six weeks that it will be in place in the mouth. Consequently, where a Titanium Reinforced membrane is used, there is no need for a filler to be applied to guarantee the space making needs.

The non-resorbable e-PTFE membrane (Gore
Tex Periodontal Material-GTPM) has the great advantage of being highly tolerated by the tissues due to its innerness. Expanded teflon is highly used in medicine in cardiovascular surgery and in orthopedics. The connective tissue forms a fibrous capsule around it without any inflammation. However, in periodontal surgery, the membrane, adapted tightly to the necks of the teeth, remains communicated to the oral environment through the crevice or pocket. For this reason, and due to its possible contamination with oral bacteria, it has to be removed. The removal is performed between 4 and 6 weeks after placement, and it requires, although it is minimal, a second surgical intervention. The need for this second surgical procedure is undoubtedly a concern for the patient, which affects his/her acceptance of this modality of treatment. It is also a concern for the clinician because it requires planning for the second surgery, including time and cost. Furthermore, it may be a concern for the outcome of therapy, because the fact that the healing area needs to be exposed makes it practically impossible to avoid manipulation of the granulation tissue growing underneath the membrane ${ }^{12)}$. It has been suggested that the exposure and handling of the healing tissue may account for the loss of some of the gain initially achieved ${ }^{13)}$.

In order to avoid the second surgical procedure for the retrieval of the membrane, resorbable barriers have been developed ${ }^{4}$. In general they belong to two groups composition wise; either are made out of collagen, or are synthetic in nature. Those made out of collagen, of different origins, will be absorbed via an enzymatic process involving collagenase. Those that are synthetic are made of different polymers and co-polymers, and are resorbed by hydrolysis. Although there are several barriers available at the present, our laboratory has been involved in studies with two of them.

Resolut barriers (W.L. Gore and Associates) are made of a copolymer of polylactic and polyglycolic acids $^{12)}$. It is composed of an occlusive film covered on both sides by randomly arranged fibers. It will initiate its process of resorption around 4 to 6 weeks, and will be completed by 8 to 9 months. Histological evaluations in dogs have determined that the process of resorption elicited an inflamma- 


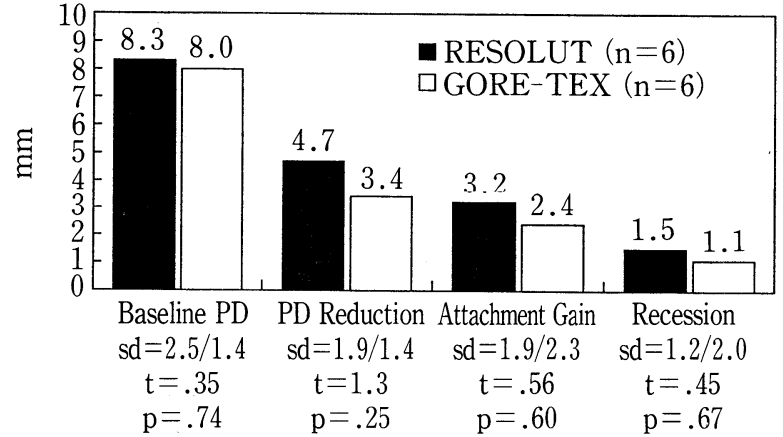

Fig. 1 Clinical Results with RESOLUT ${ }^{\circledR}$ Regenerative Material and GORETEX $^{\text {TM }}$ Regenerative Material 12 Month Comparison-Intrabony Defects (Deepest Pocket).

tory response that is limited to the location of the membrane, and that it does not interfere with the process of regeneration ${ }^{12)}$. When the results were compared to those achieved with the non-resorbable Gore-Tex Periodontal Material (GTPM), the gold standard, no differences were found in the amount of connective tissue attachment, bone or cementum deposition $^{12)}$. Furthermore, studies were performed in monkeys comparing Resolut with an open flap debridement (negative control) in the treatment of chronic class II furcations ${ }^{14)}$ and two-wall intrabony pockets ${ }^{15)}$. The results showed significantly better outcome when the barrier was used in all components required for regeneration: cementum, bone, and connective tissue fiber attachment. Histological evaluations with polarized microscopy showed clearly the attachment of periodontal ligament fibers into the newly deposited cementum, thus reestablishing the presence of the Sharpey fibers ${ }^{14,15)}$.

A multicenter study evaluating the effectiveness of Resolut in treating Class II furcations and intrabony pockets reported favorable results one year after treatment with probing depth reductions of around $3 \mathrm{~mm}$, and $2.5 \mathrm{~mm}$ of gain in clinical attachment level in Class II furcations, and $4 \mathrm{~mm}$ probing depth reductions and gains in clinical attachment of $3 \mathrm{~mm}$ in two-three wall intrabony pockets $^{16)}$.

Resolut was also compared to GTPM in the treatment of Class II furcations and intrabony pockets

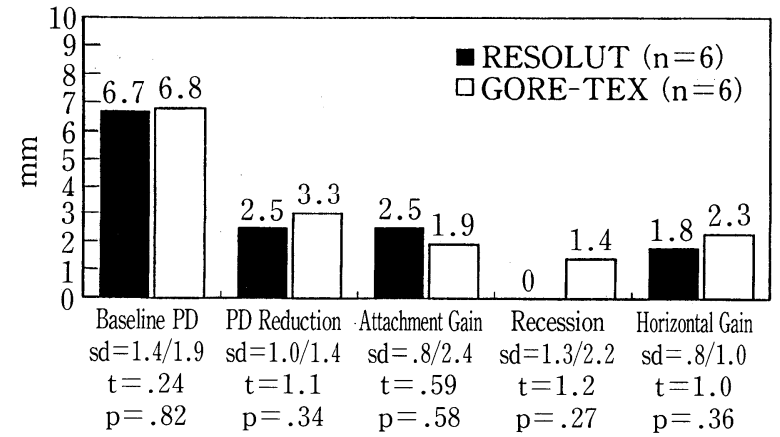

Fig. 2 Clinical Results with RESOLUT ${ }^{\circledR}$ Regenerative Material and GORETEX $^{\mathrm{TM}}$ Regenerative Material 12 Month Comparison-II Furcation Defects (Deepest Pocket).

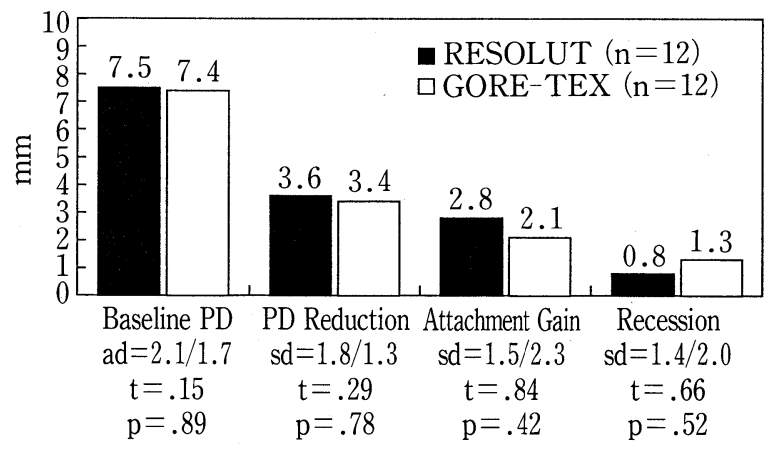

Fig. 3 Clinical Results with RESOLUT $^{\circledR}$ Regenerative Material and GORETEX $^{\mathrm{TM}}$ Regenerative Material 12 Month Comparison-All Defects (Deepest Pocket).

one year after treatment ${ }^{17)}$. Each subject provided two comparable defects, and the assignment to the type of membrane was at random. Results indicated similar changes in all the clinical parameters evaluated with non-significant statistical outcomes (Fig. 1 3).

Guidor matrix barrier (Guidor, AB, Sweden) is made out of polylactic acid with the addition of a citric acid ester for malleability ${ }^{2}$. It is a bilayered structure designed to facilitate integration and stabilization. In an animal model we have found similar regenerative capabilities in furcation defects when Guidor or Resolut resorbable membranes were used ${ }^{18)}$. Its clinical effectiveness in the treatment of intrabony defects has been described recently, one year after the treatment of 203 consecutive 


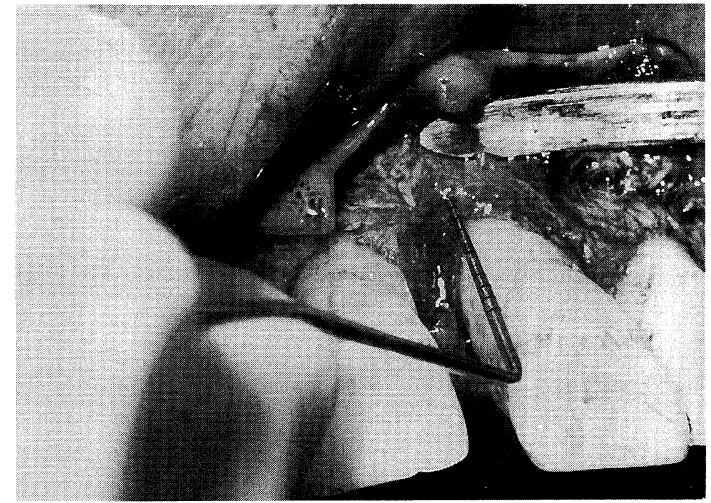

Fig. 4-a $2 \sim 3$ wall intrabony defect with significant bony dehiscence affecting the central incisor.

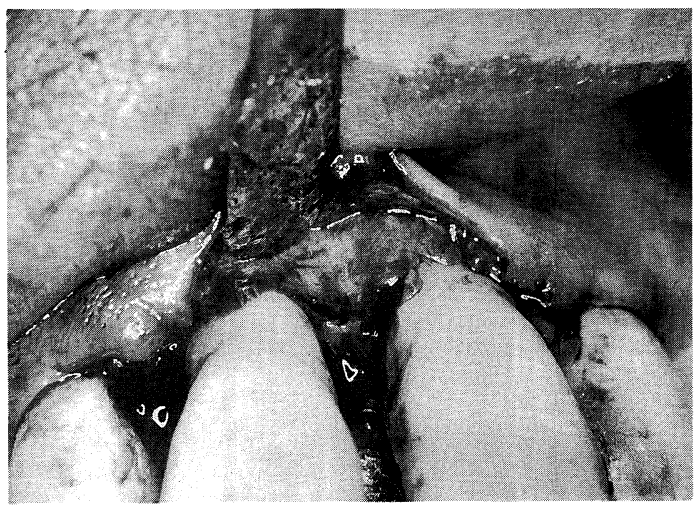

Fig. 4-c Re-entry one year after treatment shows new bone not only filling the intrabony defect, but also coronally to the alveolar crest. A physiologic bony architecture has been restored.

defects ${ }^{2}$. In a comparative study including 30 patients with intrabony defects, 15 were randomly treated with Guidor matrix and 15 with Gore Tex Periodontal Material ${ }^{19}$. The results one year after therapy showed in general similar results. Upon reentry the bone fill of the defect recorded showed no statistical difference, although the values were higher for GTPM than for Guidor (58\% versus 44\% respectively).

In essence, what transpires from this review, based mainly in clinical and animal research originated from our laboratory, is that the results achieved with guided tissue regeneration are very similar when similar defects are considered, in-

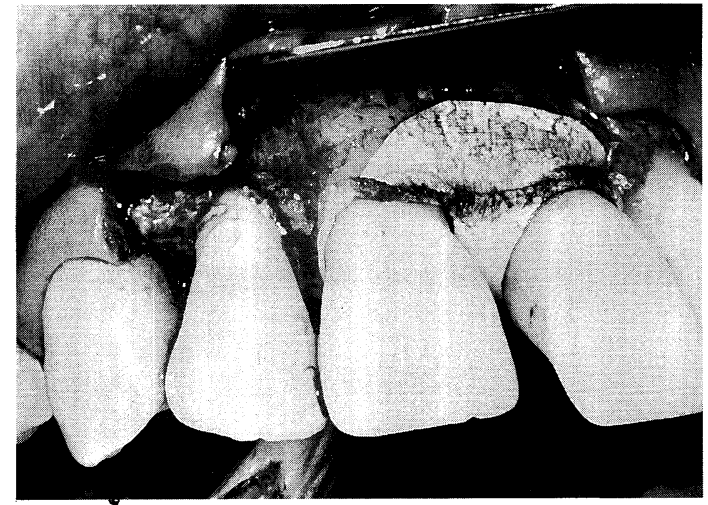

Fig. 4-b Interproximal GTPM membrane adapted (The membrane was removed after 6 weeks).

dependently of the barrier applied. Of course, all the barriers tested fulfill the basic requirements of an ideal material for $\mathrm{GTR}^{20)}$.

There are however, a couple of issues that need to be reviewed. It has been shown that during the initial healing, the vascularization of the area will be impaired when non-resorbable membranes are used. Resorbable barriers, on the contrary, will permit an early reestablishment of the vascularization in the area of the barrier ${ }^{21)}$. This may account for the favorable tissue response.

Another issue that is necessary to be considered is the effect of the barriers on healthy sites. When interproximal intrabony defects in particular are treated, the membrane necessarily needs to cover healthy areas to isolate the defect both on the involved tooth and the neighboring tooth. Evaluating the effect of the barrier on these healthy sites one year after treatment we have reported values of loss of attachment and loss of bone that are statistically significant (around $1 \mathrm{~mm}$ ). Although these changes can be considered clinically insignificant, the ranges shown may be in some instances of clinical significance ${ }^{22)}$.

In summary, enough data have been reported to support the predictability of guided tissue regeneration procedures using different mombrancs. As with any other periodontal technique, proper diagnosis and case selection are mandatory, since GTR is only an additional technique within the periodontal armamentarium. It is a specific technique for specific problems. Intrabony defects (Fig. 4) 


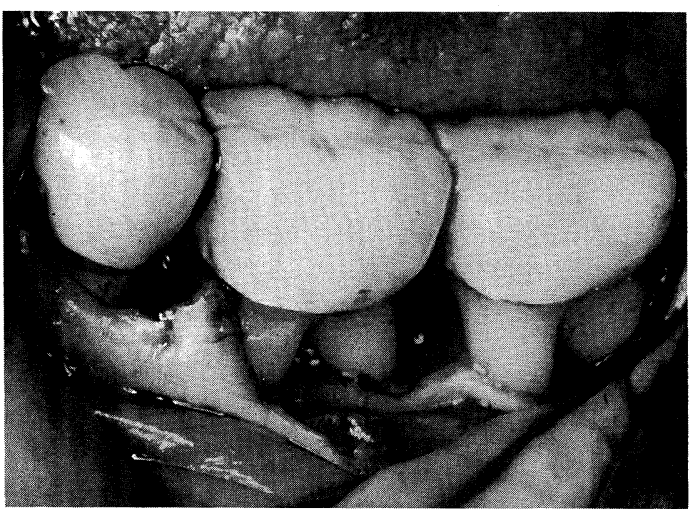

Fig. 5-a Class II furcation defects affecting both molars.

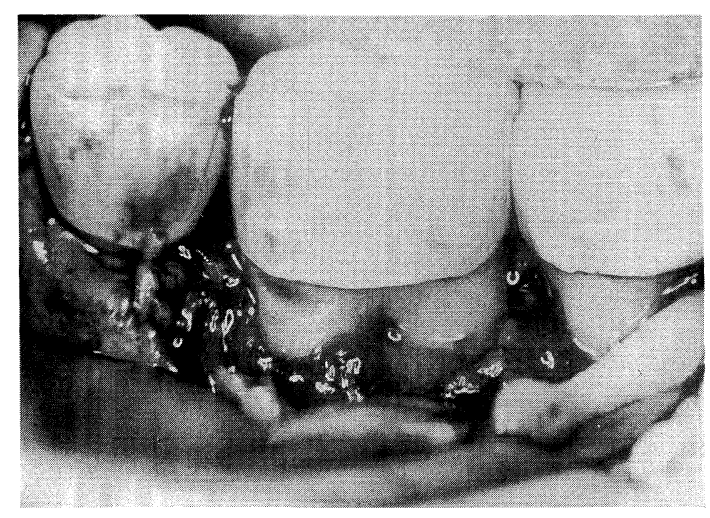

Fig. 5-c, d Upon reentry one-year after treatment bone is filling both furcations.

and Class II furcations (Fig. 5) represent the most predictable indications, when risk factors are excluded, and defect characteristics are properly evaluated.

If this is done, GTR will allow the periodontist to treat isolated teeth with advanced disease that ycars back wcrc considcrcd candidatcs for cxtraction. This is the strong point of GTR, because when overall results are compared with those achieved with conventional treatment, even scaling and root planing alone, the long term outcome of therapy is so positive that it is very difficult to document a difference. Granted, for this to be achieved proper maintenance is mandatory, as with any other chronic disease. Guided tissue regeneration is not an exception, since proper maintenance is also required to provide stable results over time on sites treated already with advanced disease, and
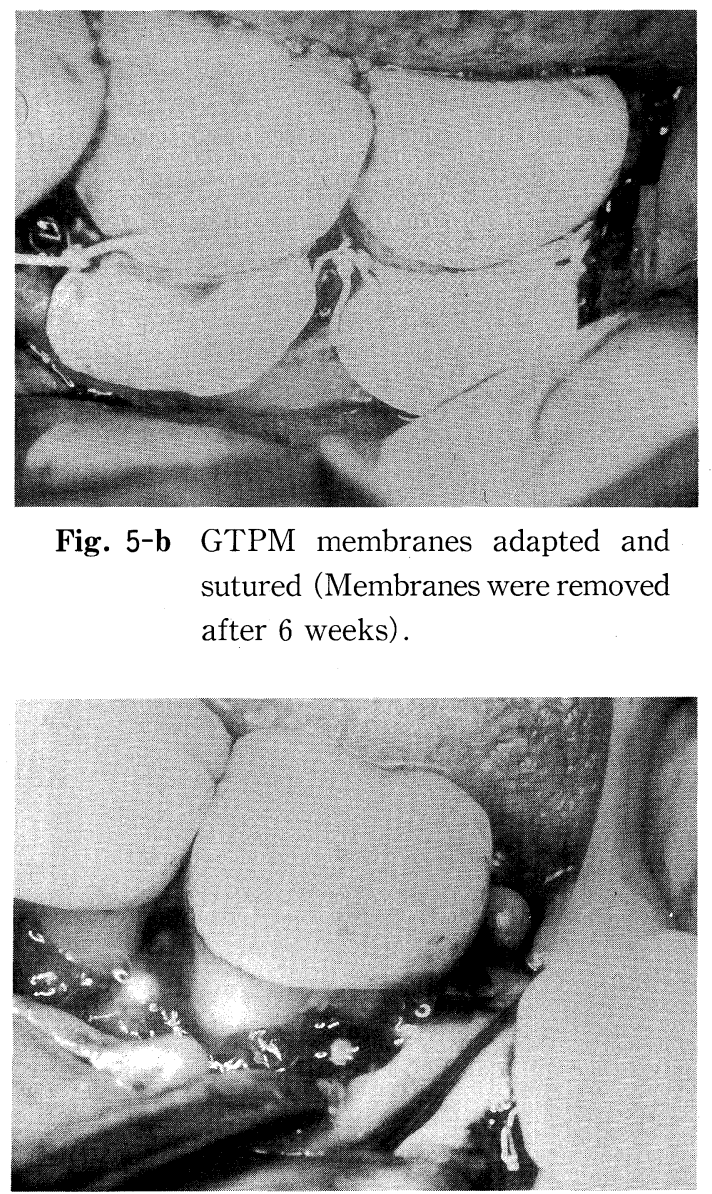

Fig. 5-b GTPM membranes adapted and sutured (Membranes were removed after 6 weeks).

with guarded prognosis for conventional therapy.

The present of periodontal therapy is exciting, the future is challenging and rewarding because more and more the profession will see the dream of true regeneration come true. The present new approaches will be enhanced by the incorporation of gcnctically cnginccred growth factors and extracellular matrices delivered to the area of interest by appropriate carriers. This will allow the treatment of periodontal defects on a biochemical basis. The possibilities to modulate the dynamics of healing are near. Regeneration is at hand.

\section{References}

1) Caffesse, R.G., Quiñones, C.R., Guided Tissue Regeneration: Biologic Rationale, Surgical Technique, and Clinical Results. Compend Contin 
Educ. Dent., Vol. XIII (3), 166-178, 1992.

2) Falk, H., Laurell, L., Ravald, N., Teiwik, A., Persson, R. Guided Tissue Regeneration: Therapy of 203 Consecutively Treated Intrabony Defects Using a Bioabsorbable Matrix Barrier. Clinical and Radiographic Findings. J. Periodontol., 68: 571-581, 1997.

3) Tonetti, M., Pini Prato, G., Williams, R. and Cortellini, P. : Periodontal regeneration of human infrabony defects. IV. Determininants of healing response. J. Periodontol., 64 : 934-939, 1993.

4) Quiñones, C.R. and Caffesse, R.G. : Current Status of Guided Periodontal Tissue Regeneration. Periodontology 2000, 9:55-68, 1995.

5) Caffesse, R.G., Smith, B.A., Castelli, W.A. and Nasjleti, C.E. : New attachment achieved by guided tissue regeneration in beagle dogs. J. Periodontol., 59 : 589-594, 1988.

6) Caffesse, R.G., Dominguez, L.E., Nasjleti, C.E., Castelli, W.A., Morrison, E.C. and Smith, B.A. : Furcation Defects in Dogs Treated by Guided Tissue Regeneration (GTR). J. Periodontol., 61: 45-50, 1990.

7) Caffesse, R.G., Smith, B.A., Duff, B., Morrison, E. C., Merrill, D. and Becker, W. : Class II Furcations Treated By Guided Tissue Regeneration in Humans : Case Reports. J. Periodontol., 61 : 510514, 1990.

8) Becker, W., Becker, B.E., Berg, L., Prichard, J., Caffesse, R.G. and Rosenberg, E. : New attachment after treatment with root isolation procedures: report for treated Class III and Class II furcations and vertical osseous defects. Int. J. Perio. And Rest. Dent., 3 (8) : 8-23, 1988.

9) Gottlow, J., Nyman, S. and Karring, T. : Maintenance of new attachment gained through guided tissue regeneration. J. Clin. Periodontol,, $19: 315$ $-317,1992$.

10) Becker, W. and Becker, B.E. : Long-term evaluation of GTR treatment of mandibular 3-walled defects. J. Periodontol., 64 : 1138-1144, 1993.

11) Caffesse, R.G., Mota, L.F. and Morrison, E.C. : The Rationale for Periodontal Therapy. Periodontology 2000, $9: 7-13,1995$.

12) Caffesse, R.G., Nasjleti, C.E., Morrison, E.C., Sanchez, R. Guided Tissue Regeneration : Comparison of Bioabsorbable and Non-Bioabsorbable Membranes Histologic and Histometric Study in Dogs. J. Periodontol., 65: 583-591, 1994.

13) Cortellini, P., Pini Prato, G. and Tonetti, M. : Periodontal regeneration of human intrabony defects with titanium reinforced membranes. A controlled clinical trial. J. Periodontol., 66:797803, 1995.

14) Hürzeler, M.B., Quiñones C.R., Caffesse, R.G., Schüpbach, P. and Morrison, E.C. : Guided Periodontal Tissue Regeneration in Class II Furcation Defects Following Treatment With a Synthetic Bioabsorbable Barrier. J. Periodontol., 68: 498-505, 1997.

15) Hürzeler, M.B., Quiñones, C.R., Caffesse, R.G., Schüpbach, P. and Morrison, E.C. : Guided Periodontal Tissue Regeneration in Interproximal Intrabony Defects Following Treatment With a Synthetic Bioabsorbable Barrier. J. Periodontol., 68:489-497, 1997.

16) Becker, W., Becker, B.E., Mellonig, J., Caffesse, R.G., Warrer, K., Caton, J.G. and Reid, T. : A Prospective Multi-Center Study Evaluating Periodontal Regeneration for Class II Furcation Invasions and Intrabony Defects After Treatment With a Bioabsorbable Barrier Membrane: 1Year Results. J. Periodontol., 67 : 641-649, 1996.

17) Caffesse, R.G., Mota, L.F., Quiñones, C.R. and Morrison, E.C. : Clincal comparison of resorbable and non-resorbable barriers for guided periodontal tissue regeneration. J. Clin. Periodontol., 24:747-752, 1997.

18) Tredinick, M.C., Sato, S., Caffesse, R.G., et al. Guided tissue regeneration: comparison of healing of class II furcation defects using two different bioabsorbable membranes. Histologic and histometric study in dogs. Manuscript in preparation.

19) Weltman, R., Trejo, P.M., Morrison, E. and Caffesse, R.G. : Assessment of Guided Tissue Regeneration Procedures in Intrabony Defects with Bioabsorbable and Non-Resorbable Barriers. J. Periodontol., 68 : 582-591, 1997.

20) Scantlebury TV. 1982-1992: A decade of technology development of guided tissue regeneration. J. Periodontol., 64 : 1129-1137, 1993.

21) Vergara, J., Quiñones, C.R., Nasjleti, C.E. and Caffesse, R.G. : Vascular response to guided tissue regeneration procedures using nonresorbable and resorbable membranes in dogs. J. Periodontol., $68: 217-224,1997$.

22) Weltman, R., Trejo, P. and Caffesse, R.G. : Effects of Expanded Polytetrafluoroethylene and Polylache Acid Barriers on Healthy Sites. J. Periodontol., In Press, 1997. 